\title{
Demographic Effects of Abortion
}

\author{
HARALD FREDERIKSEN, M.D., and JAMES W. BRACKETT
}

A GROWING NUMBER of countries are liberalizing their laws governing abortion. The degree of permissiveness varies; some countries now permit abortion virtually "on demand;" others accept social or economic reasons; some accept medical reasons only. The justification for enacting more permissive laws also varies. Some countries simply state that a woman has the right to decide whether her child will be born. Others express the hope that liberalization of the abortion laws will eliminate the evils of illegal abortion. Still others indicate an interest in easing the social and economic situation of individual families. However, the reasons given for liberalizing abortion laws rarely, if ever, include explicit concern about overpopulation.

Regardless of the stated reason for enacting permissive abortion laws, it is reasonable to assume that the more permissive laws affect fertility levels. In this paper, we attempt to quantify the demographic consequences of more liberal abortion laws in countries for which adequate data are available and which have had liberal abortion laws for sufficient periods to permit anaylsis of their demographic significance. Since abortions for medical reasons only

The authors are with the Population Service, Office of the War on Hunger, U.S. Agency for International Development, Department of State. Dr. Frederiksen is chief and Mr. Brackett is deputy chief of the population and program analysis division. The views expressed are the authors' and do not necessarily represent the opinion or reflect the policy of any governmental agency. are not likely to have demographic significance, we have focused on countries which permit abortion on demand or for social and economic reasons (see table).

Sweden, Japan, and a number of countries in eastern European have had permissive abortion laws for some time (Sweden-22 years, Japan-20 years, and eastern European countries-12 to 13 years). With the notable excepttion of the Soviet Union, statistics on births and abortions are available for these countries. In some of these countries, sizable numbers of illegal abortions were reportedly already being performed before the more permissive laws were promulgated.

\section{Methods}

To obtain a better understanding of the demographic impact of abortion, we used total fertility rates. Total fertility rates are the sum of the age-specific fertility rates (hirths per 1,000 women at each age from 15 to 49 years). Likewise, we calculated the total rates for legally induced abortions and, where possible, for "other" abortions, as well as for pregnancies. These measures indicate the number of such events that would occur to 1,000 women if the set of age-specific rates for such events in the indicated year were to remain in effect throughout their reproductive lifetimes.

The following four classes of prototype situations were examined.

1. Large-scale abortion is introduced into a population in which contraception is widely practiced.

2. Large-scale abortion is introduced into a 
population in which illegal abortion is widely practiced.

3. Large-scale abortion is introduced into a population in which contraception is not widely practiced.

4. Large-scale contraception is introduced into a population in which abortion-legal or illegal-is widely practiced.

\section{Class 1 Prototype Situations}

Bulgaria. European countries with permissive abortion laws best fit the first class of prototype situations in which abortion is introduced into a poulation widely practicing contraception. Bulgaria was the first eastern European country to liberalize its abortion laws (February 1956). The number of legal abortions increased from only 1,100 in 1954 to 31,700 in 1957 and to 83,000 in 1963. (Legal abortions were not separately reported for 1955 and 1956.) "Other" abortions declined from a total number of 17,500 in 1954 to 14,500 in 1957 and then rose to a peak of 21,100 in 1962 before decreasing to 20,500 in 1963 (1).

The trends in the total rates for pregnancy, fertility, and abortion in Bulgaria during the

\section{Permissiveness of abortion laws and levels of birth rates in selected countries}

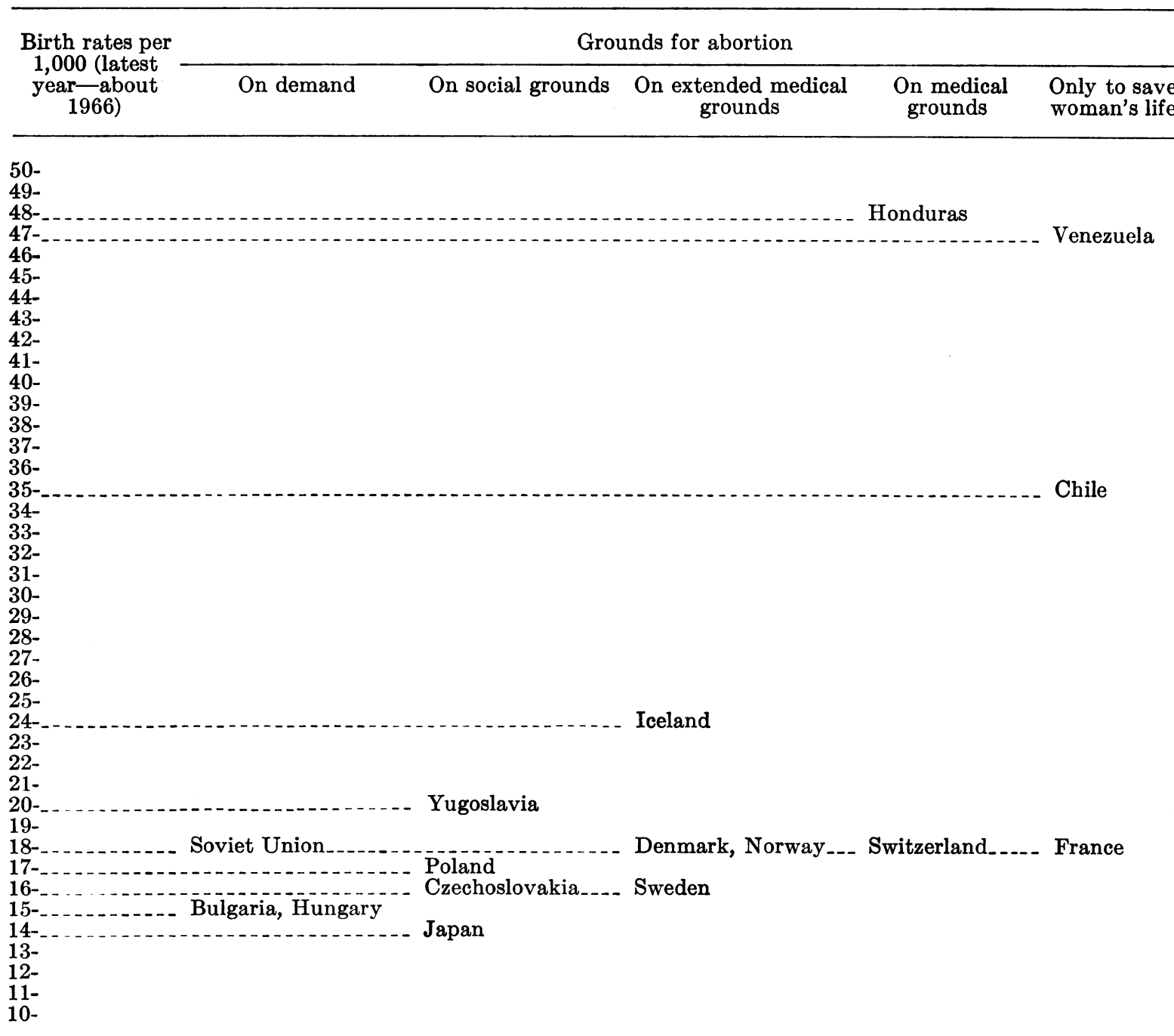

Sources: Roemer, R.: Abortion law: The approaches of different nations. Amer J Public Health 57: 1906--1922, November 1967; United Nations: Population and Vital Statistics Report. U.N. statistical papers ser. A. Apr. 1, 1968. 
Figure 1. Total rates of pregnancy, fertility, legal abortion, and other abortion, Bulgaria, 1953-63

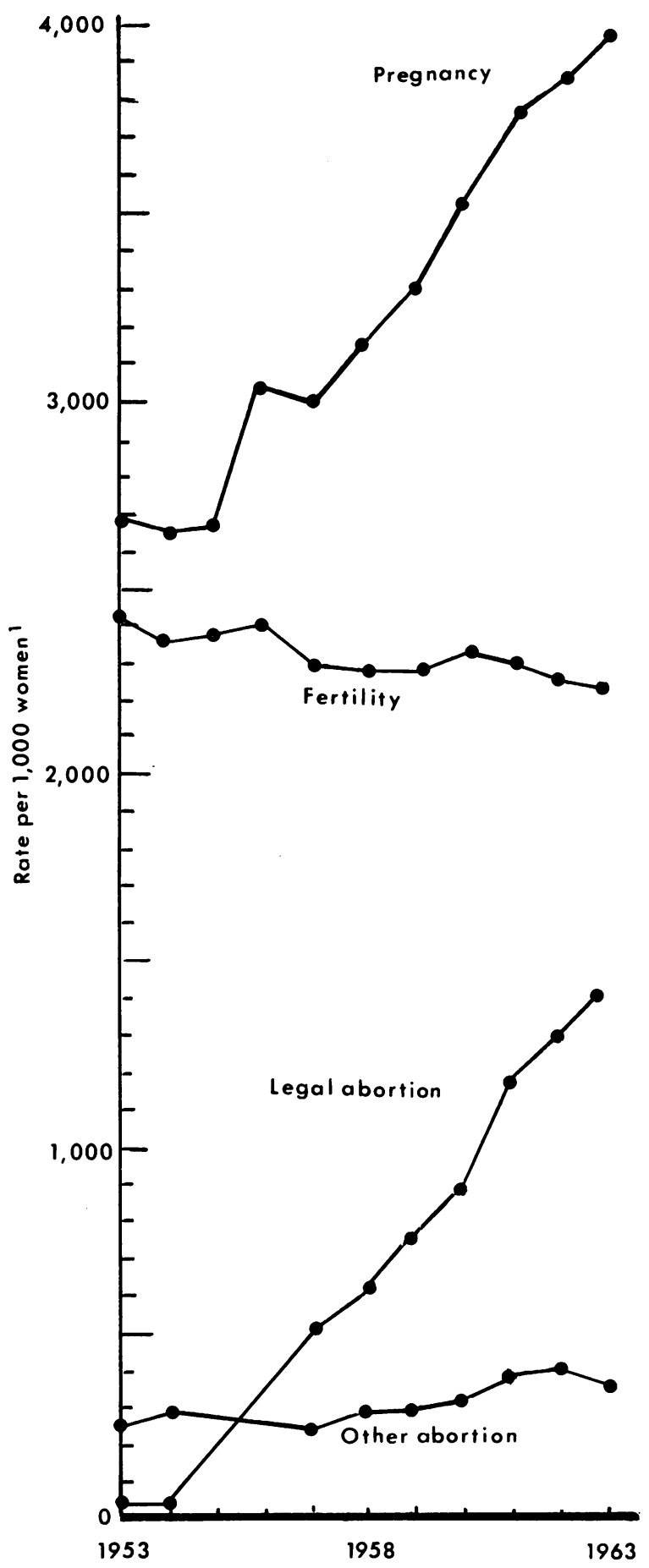

"For definition of the total rates, see "Methods" section.

SOURCES OF BASIC DATA : references $1-4$. period 1953-63 are shown in figure 1. The fact that the total fertility rate was already fairly low before the abortion laws were liberalized indicates a high degree of fertility control. (The total fertility rate for 1954, of 2,400 , indicates that, as of that year, a Bulgarian woman could expect to have, on the average, 2.4 children in her reproductive lifetime.) Although the total rate for legal abortion increased sharply-from near zero in 1954 to about 1,400 in 1963, the total fertility rate declined only slightly. During the period 1954-63, the total rate for legal abortion increased about 10 points for every point of decline in the total fertility rate.

The sharp rise in the total rate of abortion in Bulgaria was associated with a sharp rise in the total pregnancy rate. Consistent with Scott's observations (1) about other eastern European countries, an increasing proportion of women in Bulgaria may have begun to rely on abortion as the principal form of birth control, practicing contraception less extensively and consistently since they knew that they could readily obtain an abortion. Moreover, when a pregnancy is terminated by abortion shortly after conception, a woman returns to the population at risk.

Heer (5) cites data from Potter (6) to conclude that, in the absence of contraception, two or three abortions are required to prevent one birth. The reason Heer gives is that the interval between two conceptions will be longer when the first one results in a live birth than when it is terminated by abortion. Potter fixed the interconception interval at approximately 9 months when the first pregnancy is terminated by abortion. This period is divided into 3 months of pregnancy, 1 month of post partum amenorrhea, and 5 months of ovulatory exposure before the second conception. When the first conception results in a live birth, the interconception interval is set at 27 months if the child is breast fed and 18 months if he is not. The 18-month period consists of 9 months of pregnancy, 2 months of post partum amenorrhea, 2 months of anovulatory cycles, and 5 months of ovulatory exposure before the second conception. Breast feeding increases the period of post partum amenorrhea to 11 months.

Hungary. In Hungary, the country with the lowest fertility in the world, the total fertility rate declined more sharply when the abortion 
Figure 2. Total rates of pregnancy, fertility, legal abortion, and other abortion, Hungary, 1949-63

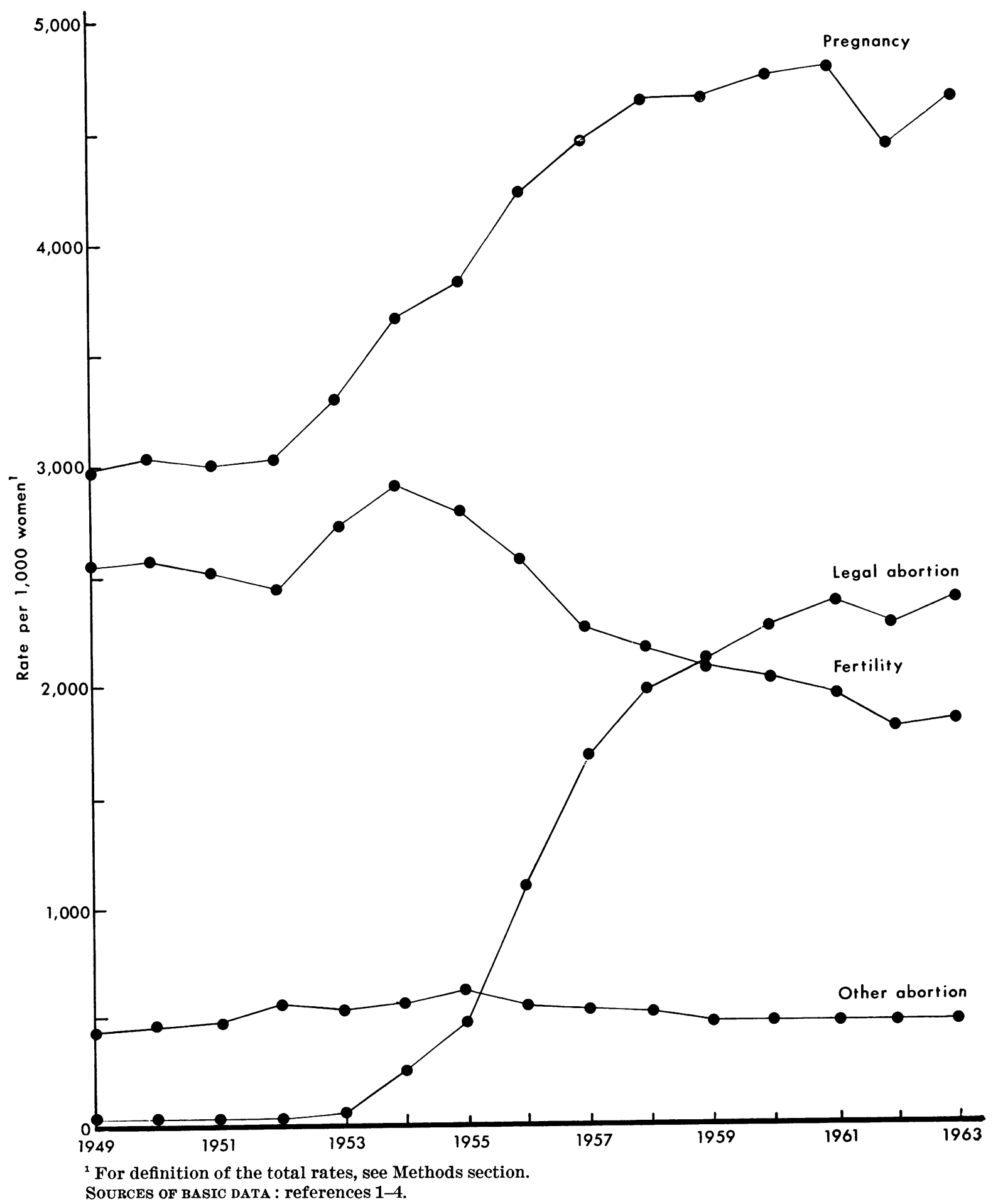


laws were liberalized than it did in Bulgaria. The increase in the total abortion rate, however, far outstripped the decline in the total fertility rate (fig. 2).

It is difficult to obtain a measure of the true decline in fertility rates in Hungary. During the period immediately preceding the liberalization of the abortion laws, the Hungarian Government had pursued a strongly pronatalist policy, which succeeded in sharply increasing the birth rate in 1954. If we take the period 1950-52 (when the total fertility rate was about 2,500) as the base period for calculation of the change after the liberalization of the abortion laws, the total fertility rate dropped by nearly 700 points, to about 1,800 in 1963.

Although Hungary's liberal abortion law dates from 1956, by late 1954 the Hungarian Government had reversed its pronatalist policy and by administrative decision had started offering abortion on more liberal terms. In 1963, the total rate for legal abortion in Hungary was nearly 2,400 , a figure which also represents the increase in the rate since the early 1950 's. Thus, the total abortion rate increased by more than 3 points for every point of decrease in the total rate of fertility.

Szabady and Klinger ( $(7)$ reported that the proportion of married women in Hungary using one or another form of contraception seems to have remained fairly constant in the 10 years following the liberalization of the abortion laws in 1956. In a 1958-60 study of married women $15-49$ years of age, 61.3 percent used some form of contraception, whereas, in a 1965-66 study, 59.9 percent of the married women of these ages used some form of contraception.

But the quality of contraceptive practice in Hungary seems to have deteriorated when abortion became more readily available. In the 10 years following the liberalization of the abortion laws, there was a shift from contraceptive methods requiring devices and foresight toward coitus interruptus. In the 1958-60 study, about half of the married women 15-49 years old who were practicing contraception reported coitus interruptus as the method of choice; in the 1965-66 study, two-thirds reported that they used this method. Couples who do not wish to be bothered with extra devices or efforts may prefer coitus interruptus, particularly when they know that abortion is readily available in the event of an unwanted conception.

Szabady and Klinger suggest that part of the shift to coitus interruptus may have been due to differences in the survey methods. In the earlier study there may have been some tendency to record the more modern methods when these methods were used in conjunction with coitus interruptus, even when coitus interruptus was the predominant method. These authors, however, seem to accept at least part of the shift to coitus interruptus as real.

The other four eastern European countries with permissive abortion laws (Czechoslovakia, Poland, Rumania, and Yugoslavia) followed to varying degrees the pattern illustrated by the case histories of Bulgaria and Hungary.

Sweden. In Sweden, a country with very low fertility, legal abortions were relatively rare, possibly because Sweden's abortion laws are more restrictive than those of the eastern European countries we have discussed. In Sweden, abortions reached their peak in 1951, but in that year less than 6 percent of the pregnancies were so terminated. By 1960, this proportion had declined to less than 3 percent. The total rate of legal abortion in Sweden in 1951 was about 125 , compared with a total fertility rate of 2,200 . By 1960, the total rate of legal abortion had dropped to about 60 , while the total fertility rate remained constant $(8,9)$.

\section{Class 2 Prototype Situations}

Since one of the primary reasons for liberalization of abortion laws has been to reduce the evils associated with large-scale illegal abortions (the second class of prototype situations), the question arises whether a large part of the apparent increase in legal abortions that generally follows such a liberalization represents a replacement of hidden illegal abortions by reported legal abortions. Such a substitution would be plausible, but there is little objective evidence for it. In fact, there is some evidence that liberalization of abortion may even increase illegal abortions.

East Germany. Mehlan (10) reviewed the incidence of births, abortions, and pregnancies in 65 localities in East Germany. He estimated the number of illegal abortions during the years 1946 to 1954 on the basis of data from 287 hos- 
pitals and from about 7,000 women in the childbearing ages, who were interviewed by 67 physicians in private practice.

Mehlan reported a sharp increase in pregnancies in 1949 and 1950 upon the introduction of the so-called social indication for legal abortion. The number of pregnancies rapidly decreased again, however, upon the restriction of legal abortions at the end of 1950 . He surmised that the ready accessibility of legal abortions and the leniency in sentencing for illegal terminations of pregnancy led to a reduced practice of contraception.

Along with the increase in pregnancies and legal abortions, Mehlan (11) found an increase in illegal abortions. Upon the restriction of legal abortions, he noted a decrease in illegal terminations of pregnancy. He explains the temporary increase in illegal abortions by noting the temporary increase in the number of pregnancies and the changes in the attitudes of women about germinating life after the abortion laws were liberalized.

Using the basic data and methods of Mellan (10), but without smoothing the basic data, we arrived at substantially the same conclusions as he did about the trends of births, abortions, and pregnancies in the 65 localities of East Germany during the years 1946-54 (fig. 3).

Suprisingly, illegal abortions, as well as births and pregnancies, increased in East Germany between 1948-50, a period in which the abortion laws were liberalized to allow abortions on social as well as on medical grounds. At the end of 1950, however, the abortion laws were again severely restricted, whereupon the upward trends of births leveled off and the trends of legal and illegal abortions and pregnancies declined in unison. Thus, neither the number of illegal abortions in East Germany, nor the number of births, was reduced by the temporary liberalization of the abortion laws.

Although in East Germany the incidence of legal abortions may not have had an obvious effect on the trend of births, nor the expected effect on the trend of illegal abortions, it is possible that in other countries liberalization of the abortion laws would result in a greater and more extensive decrease in the incidence of illegal abortions. Many women, however, may resort to illegal abortions because they may be secret.
Legal and illegal abortions may attract a different kind of client, in different circumstances, and with different reasons for seeking an abortion. Thus, we should not asume that liberalization of abortion laws will result in the replacement of all, or even most, illegal abortions with legal terminations of pregnancy. Nor should we assume that an increase in one kind of abortion will necessarily be associated with a decrease in another kind. Apparently such a decrease did not occur in East Germany (fig. 3 ).

Aresin (12), using a method entirely different from ours to examine the effects of liberalization of the abortion laws on the frequency of illegal abortions in East Germany, arrived at much the same conclusion as we did. He found that the introduction of the social indication for abortion had not reduced febrile abortions, which are considered to be a gynecological indicator of the frequency of illegal terminations of pregnancy.

Other eastern European countries. The situation may have been somewhat different in other eastern European countries which adopted liberal abortion laws some years later than East Germany, but had let these more liberal laws remain in effect. Hirschler (13) concluded that the sharp increase in legal abortions in Hungary after the liberalization of the abortion laws was more apparent than real, being the result of replacing an estimated 100,000 previously hidden illegal abortions with reported legal abortions. But his estimates of the numbers of hidden illegal abortions before and after the laws were liberalized were based on the assumption that the pregnancy rate had remained constant before and after the liberalization. It would be circular reasoning to conclude, however, on the basis of such an assumption, that the total number of abortions in Hungary had increased very little. If we assume a constant pregnancy rate, one legal abortion would equal one prevented birth, but such a conclusion is the inevitable artifact of the assumption.

\section{Class 3 and 4 Prototype Situations}

Japan at different points in time seems to fit two of the classes of prototype situations. When a eugenics protection law was enacted in 1948, contraception apparently was not widely practiced in Japan. A survey conducted by the 
Figure 3. Number of pregnancies, births, and abortions in 65 localities of East Germany, 1946-54.

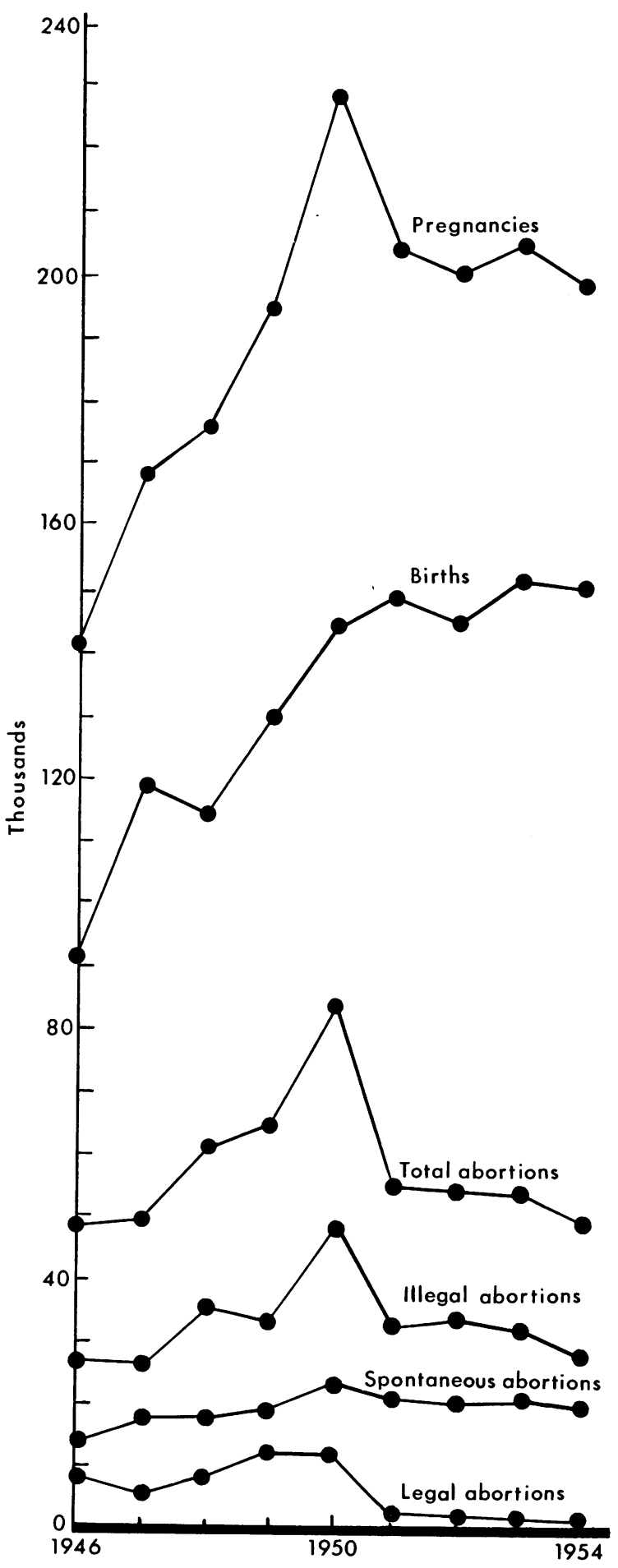

Source OF BASIC DATA : reference 10.
Mainichi newspapers in 1951 indicated that, among couples in which the wife was under 50 years of age, only one couple in five was practicing contraception. Before 1950, the proportion was generally believed to be even lower $(14,15)$. Thus, Japan in the late 1940's seems to represent the third class of prototype situations-a population not widely practicing contraception into which large-scale abortion is introduced.

In the late 1950's, however, Japan appears to fit the fourth class of prototype situations, in which contraception is extended widely to a population already widely practicing abortion. In 1955, the Mainichi newspapers found that one couple in three was practicing contraception and that more than half of the couples surveyed had done so at some time in their lives. By 1965, more than half of the couples reported that they were currently practicing contraception.

As a result of the legalization of abortion in Japan in 1948, legal abortions increased sharply. There were 246,000 legal abortions in 1949 and 489,000 in 1950 ; after a peak of $1,170,000$ in 1955 , the number declined to less than 900,000 in 1964 (15). The total rate of legal abortion followed a similar pattern. It increased from about 400 abortions per 1,000 women in 1949 to a peak of 1,600 in 1955 and then declined to about 1,100 by 1964 (fig. 4).

Contrary to the pattern observed for Bulgaria and Hungary, the total pregnancy rate, as well as the total fertility rate, declined in Japan after the abortion laws were liberalized. This result indicates that contraception also contributed to the decline in fertility that occurred in Japan in the early 1950's. Subsequently, as contraception became more prevalent, there was a concomitant and commensurate decline in the total rate of legal abortion as well as in the total fertility and pregnancy rates (fig. 4).

It is surprising to find so little correlation in cross-sectional and longitudinal comparisons of the rates, and of the increase in the rates, of legal abortions with the levels, and the decrease in the levels, of the crude birth rates in Japan (figs. 5 and 6 ).

We used crude birth rates to evaluate the demographic significance of legal abortions in the 46 prefectures of Japan since total fertility rates or gross reproduction rates were not avail- 
Figure 4. Total rates of pregnancy, fertility, and legal abortion, Japan, 1949-63

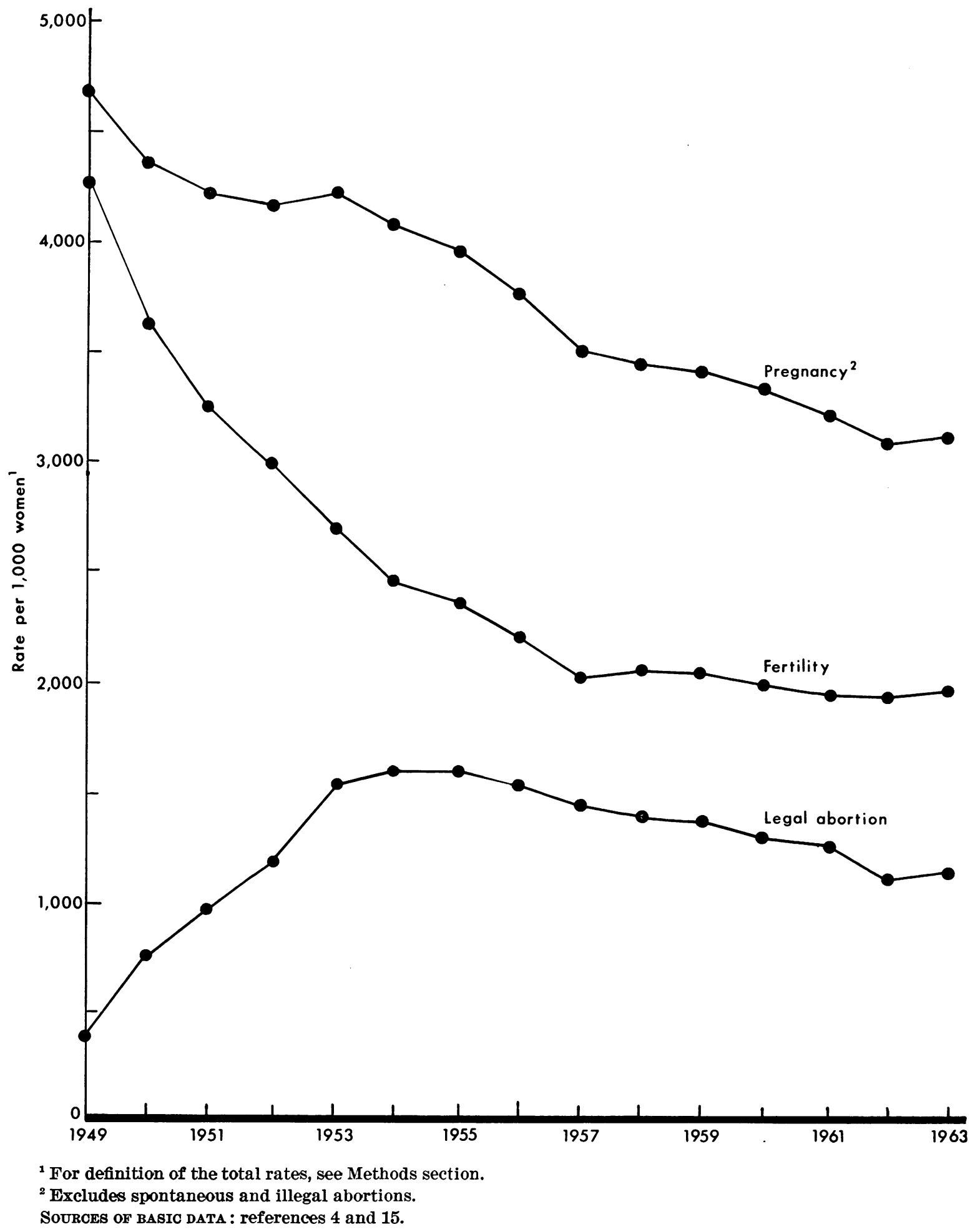


able for the entire period under study. It was possible, however, to compare the crude birth rates with the gross reproduction rates in the prefectures in 1955 , a year when the correlation was almost perfect $(r=0.97)$.

These comparisons take postwar data from 46 prefectures of Japan at a point in time (1964) and also over a period of time (1947-64) at face value. Incidentally, the magnitudes of the increases in the rates of legal abortion between 1947 and 1964 (fig. 6) are the same as the magnitudes of these rates for 1964 (fig. 5). The abortion laws were liberalized in Japan in 1948. Since, however, legal abortions were uncommon, if not absolutely absent before 1948, the level of legal abortions in 1964 is approximately the same as the increases in legal abortions from virtually zero in 1947.

Although the lack of correlation between the rates of legal abortion and the birth rates may reflect inadequacies in the reporting of legal abortions in some of the prefectures, it may also

Figure 5. Scatter diagram of the rates of legal abortion and of the birth rates in the 46 prefectures of Japan, 1964

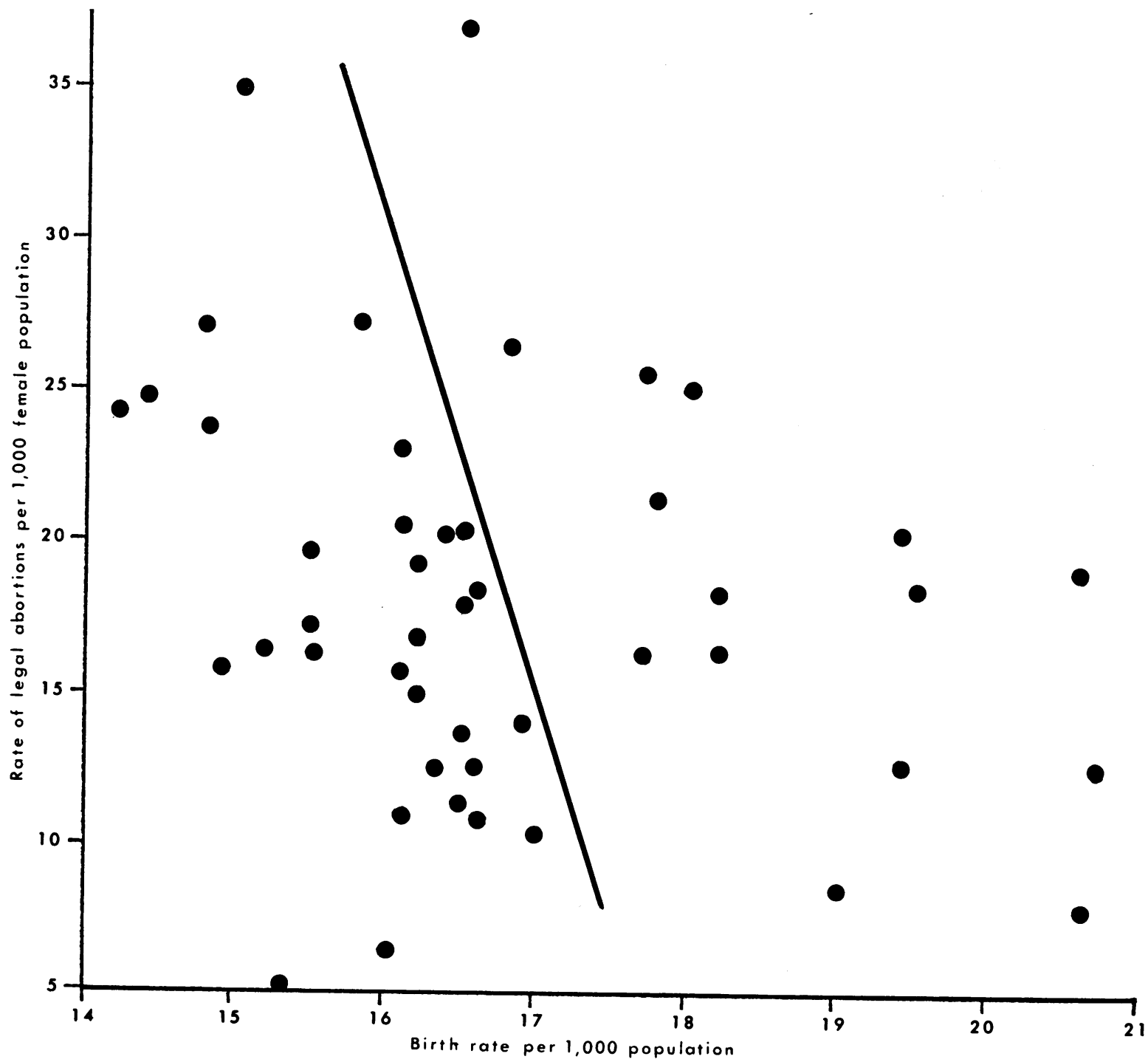

Regression line : $B R=17.94-0.0636 A R$.

$\left(r^{2}=0.069\right)$.

SOURCE OF BASIC DATA : reference 15. 
reflect, at least in part, the relatively greater. importance of contraception than of abortion as a determinant of fertility patterns in Japan, at least since 1953 (fig. 4).

But any conclusions concerning the relation between the trends of abortions and births based on crude rates must remain tentative until confirmed by age-specific data from the prefectures, data which so far we have not been able to obtain for the entire period under study.

To assume that the Japanese experience indicates the pattern which other countries will inevitably and closely follow would be unwise. Japan has had a long history of modernization. Before World War II, it had a highly industrialized, highly urbanized, and highly literate population. For Japan, this catastrophic war resulted in substantial destruction of cities, a major loss of life, and military occupation. Japan lost her extensive overseas territories and was forced to absorb into the home islands large numbers of Japanese nationals from these territories (14).

Some type of family planning was being practiced by a significant number of couples in Japan before World War II, as evidenced by the intermediate levels of Japan's birth rates in the late 1930's. Some Japanese delayed marrying, some relied on contraception, and some resorted to illegal abortion. But the Japanese government, adopting a pronatalist policy, severely repressed the practice of induced abortion before and during the war. After the war, illegal abortions increased. The situation completely altered in 1948 when the abortion laws were liberalized. A large-scale extension of the practice of abortion followed (15).

\section{Conclusion}

Before we present our conclusions, we should note that there remains a wealth of largely unexploited data which might indicate the effects of offering abortion on more liberal terms in various situations. Perhaps one reason for the lack of exploitation of this material is that much of it is available only in the language of the respective countries. For example, we found a considerable quantity of readily accessible data on the situation in Hungary in articles which had not been translated. Since neither of us reads Hungarian, our use of these materials had to be confined to translations of the tables and to the brief summaries in English that some of the Hungarian journals provided, plus a few additional items made available to us through our limited translation services. We hope others will have greater opportunities to examine these data and the relevant analyses.

Since one of the primary reasons for liberalization of abortion laws has been to reduce the evils of large-scale illegal abortion, it has been commonly assumed that the increase in legal abortions that follows such liberalization represents a replacement of hidden illegal by reported legal abortions. But one cannot assume that liberalization of the abortion laws will invariably result in the replacement of all, or even most, illegal abortions with legal terminations of pregnancy. In fact, in East Germany, an increase in legal abortions following liberalization of the abortion law was accompanied by an increase in illegal abortions.

Review of the experience of Sweden, Japan, and the eastern European countries shows that there is no consistent relationship between the trends of legal abortions and of reproduction. These trends may either be positively or negatively correlated, depending upon the demographic context and the changing pattern of contraceptive practice.

In countries where contraception is already practiced by a substantial proportion of the population, permissive abortion laws may contribute more to a dimunition of the effective practice of contraception than to a reduction in the birth rate below the level already obtained by contraception.

Conversely, when contraception is introduced into a country where abortion is widely practiced, declines in abortion rates may accompany declines in pregnancy and fertility rates.

We have seen what happens when the abortion law is liberalized in countries where contraception has been extensively practiced. Conversely, we have seen what happens when the practice of contraception is extended in countries where abortion has been freely practiced. But, because we lack more clear-cut and generalizable case histories than the one for Japan, we do not know what would happen if abortion were to be facilitated in a country where con- 
Figure 6. Scatter diagram of the increase in the rates of legal abortion and of the decrease in the birth rates in the 46 prefectures of Japan between 1947 and 1964

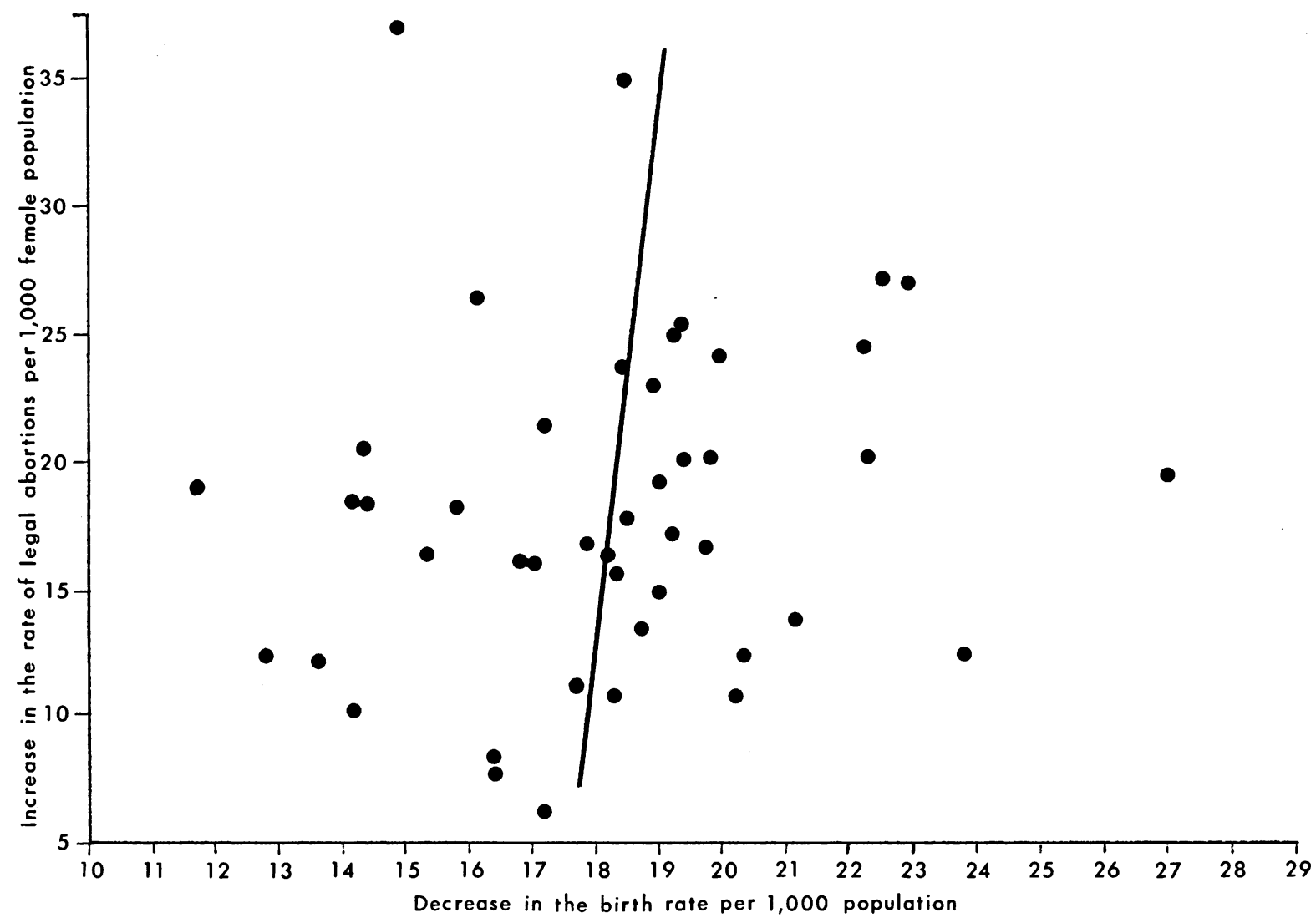

Regression line : increase $B R=17.44+0.0464$ decrease $A R$. $\left(r^{2}=0.009\right)$.

SOURCES OF BASIC DATA : references 15 and 16.

traception had not been very prevalent previously.

The relative acceptability and feasibility of abortion and contraception as alternative methods of birth control in traditional societies with high levels of fertility remains to be established. Moreover, it remains to be determined whether abortion and contraception would be more effective and efficient in combination than contraception extended singly.

\section{Summary}

The demographic effects of abortion were evaluated in these four prototype situations: large-scale abortion is introduced where contraception is widely practiced; large-scale abortion is introduced where illegal abortion is widely practiced; large-scale abortion is introduced where contraception is not widely practiced; and large-scale contraception is introduced where abortion is widely practiced.

One might assume that the increase in legal abortions that follows the liberalization of the abortion law represents a replacement of hidden illegal abortions by reported legal abortions. In the particular prototype situation we examined, however, an increase in legal abortions was accompanied by an increase in illegal abortions.

Where contraception is already widely practiced, it appears that permissive abortion laws may contribute more to a diminution of the effective practice of contraception than to a reduction in the birth rate below the level obtained by contraception. Conversely, when contraception is introduced where abortion is widely practiced, declines in abortion rates may accompany declines in pregnancy and fertility rates.

For lack of clear-cut and generalizable case 
histories, we do not know what would happen if abortion were to be facilitated where contraception has not been widely practiced. The relative acceptability and feasibility of contraception and abortion as alternative methods of birth control in traditional societies with high levels of fertility remain to be established. Moreover, it remains to be determined whether these two methods of birth control would be more effective and efficient in combination than contraception extended singly.

\section{REFERENCES}

(1) Scott. L.: Projections of the population of the Communist countries of eastern Europe by age and sex : 1965-1985. U.S. Bureau of the Census, series P-91, No. 14. U.S. Government Printing Office, Washington, D.C., 1965.

(2) Tietze, C. : The demographic significance of legal abortion in eastern Europe. Demography 1 : 19125 (1964).

(3) Klinger, A.: Demographic effects of abortion legislation in some European Socialist countries. In Proceedings of the United Nations World Population Conference, Belgrade, Yugoslavia, Aug. 30-Sept. 10, 1965. United Nations, New York, 1967, vol. 2, pp. 89-91.

(4) Demographic Yearbooks. United Nations, New York.

(5) Heer, D. M.: Abortion, contraception and population policy in the Soviet Union. Demography 2 : 531-539 (1965).
(6) Potter, R. G., Jr.: Birth intervals: Structure and change. Pop Stud 16: 155-166, November 1963.

(y) Szabady, E., and Klinger, A.: The 1965-1966 Hungarian study on fertility, family planning and birth control. Demográfia (Budapest) 9: 135-161 (1966).

(8) Statistisk Ărsbok för Sverige, 1967. Statistiska Centralbyrån, Stockholm.

(9) Tietze, C: Abortion in Europe. Amer J Public Health 57 : 1923-1932, November 1967.

(10) Mehlan, K. H. : Abortstatistik und Geburtenhäufigkeit in der Deutschen Demokratischen Republik. Deutsch Gesundh 10: 1941-1972, December 1955 .

(11) Mehlan, K. H.: In Internationale Abortsituation, Abortbekämpfung, Antikonzeption. Edited by K. H. Mehlan. Georg Thieme, Leipzig, 1961, pp. $55-60$.

(12) Aresin, N.: Grundsätzliche Gedanken zur Frage der Schwangerschaftsunterbrechung. Deutsch Gesundh 13: 1178, September 1958.

(13) Hirschler, I: In Internationale Abortsituation, Abortbekämpfung, Antikonzeption. Edited by K. H. Mehlan. Georg Thieme, Leipzig, 1961, pp. 114-122.

(14) Taeuber, I.: The population of Japan. Princeton University Press, Princeton, N.J., 1958.

(15) Muramatsu, M.: Japan's experience in family planning-past and present. Family Planning Federation of Japan, Inc., Tokyo, 1967.

(16) Japan Statistical Yearbook, 1949. Executive Office of Statistics Commission and Statistics Bureau of the Prime Minister's office. Nihon Statistical Association, Tokyo.

\section{Dissolving Bottles}

A 1-year $\$ 54,291$ Public Health Service grant has been awarded to Dr. Samuel F. Hulbert, assistant professor of ceramic and metallurgical engineering at Clemson University, to develop a glass container that can be dissolved in water for disposal.

The container would be made of a special glass that would dissolve after it is broken. A water-resistant coating over the outer and inner surfaces of the bottles and containers would keep them from dissolving while in use.

A trash collector could pick up bottles or containers made of this glass, haul them to a central point, break them, and dissolve them by placing them in a vat of water. 